\title{
Strategies of Cultivating Students' Intercultural Communication Competence in Senior High School English Teaching
}

\author{
Ling REN \\ School of Foreign Languages, Anshan Normal University, \\ Anshan, China \\ Email: renling416@163.com
}

\author{
Lihua CUI \\ School of Foreign Languages, Anshan Normal University, \\ Anshan, China \\ Email: lihuacui0220@163.com
}

\begin{abstract}
Components of intercultural communicative competence include attitudes, knowledge and skills, and more. In high school English teaching, the following strategies can be taken to develop students' intercultural communicative competence. First of all, teachers should pay great attention to teaching cultures. While properly coping with the relationship between language ability and communicative competence, teachers should also focus on the comparison of similarities and differences between Chinese and western cultures, cultivating students' awareness of intercultural communication and sensitivity. Second, teachers must hold a correct view of the relationship between teaching and learning, and develop students' ability of self-learning and self-improvement by means of teaching English knowledge and improving language ability. If permitted, the background of foreign teachers can be efficiently used. Finally, strengthening students' cultural awareness of their native languages is very important, which can be of great help to promote their language and culture competence, thus to cultivate students' intercultural communication ability.
\end{abstract}

Keywords-Senior High School; English Teaching; Intercultural Communication Competence; Strategies

\section{INTRODUCTION}

In the context of globalization, the talents needed in the future society will face more international and intercultural exchanges. Meanwhile, essential intercultural communication skills, global awareness, international understanding and information literacy are all closely linked with foreign languages. English is a subject of foreign language behind which there is a culture and a kind of thinking. When students learn English, they not only need to master it, but also to understand the cultures of English-speaking countries and the habits of their way of thinking. The English subject cannot be separated from language, culture and thinking. Therefore, the revision of the "National English Curriculum Standard" puts forward four key competence for English subject, including language ability, cultural character, thinking quality and learning ability. As a whole, the four key competence forms an integration of mutual influence and mutual promotion, in which language ability is considered as the basic element, cultural character as the value orientation, thinking quality as the mental security, and learning ability as the development conditions [1]. The formation of key competence of English subject should be shifted from the overall emphasis on cultivating subject knowledge and skills to the socialist constructors and successors who possess Chinese feelings, international perspectives and intercultural communication skills.

In senior high school English teaching, teachers should cultivate students' cultural knowledge and understanding, such as the inheritance and dissemination of Chinese culture, the understanding and respect of the foreign culture and the cultural differences among different countries. In addition, teachers ought to cultivate students' intercultural communication skills in order to help them improve their intercultural skills, and respect and appreciate with people from different cultures and countries. What's more, through fostering international perspective, students can take a deeper and broader perspective to solve different problems, thus to cope with the collision and fusion of different cultures using a right attitude and wisdom.

\section{CONCEPT OF INTERCUltural COMMUNiCATIVE COMPETENCE}

Intercultural communicative competence refers to the ability of people from different ethnic backgrounds and cultures to successfully communicate with each other. Obviously, the cultivation of intercultural communicative competence is an important goal of foreign language teaching [2]. In order to understand the connotation of intercultural communicative competence, students must pay attention to two important concepts. One is the effectiveness of communication, which refers to the ability to achieve their intended purpose through communicative behaviors. And the other is the appropriateness of communication, which means the ability to use the most appropriate communicative behaviors in a particular social environment or occasion.

Generally speaking, three kinds of basic factors are included in intercultural communicative competenceemotional factors, cognitive factors and behavioral factors. Emotional factors here refer to one's emotions or attitudes in intercultural communication. For example, students with intercultural competence can demonstrate positive emotions before, during and after intercultural communication. Moreover, 
they can recognize the existence of cultural differences, respect differences among different cultures and have high intercultural sensitivities. At the same time, they have a rational and objective understanding of themselves and can overcome the tension in communication. In addition, they are willing to express themselves openly and honestly, and listen to each other's opinions as loyal listeners. Cognitive factors refer to intercultural awareness. That is, students' cognitive changes to the surrounding world based on the understanding of their own cultures and foreign cultures. Behavioral factors refer to the ability and skills to conduct effective, appropriate intercultural communication, such as the ability to acquire and use language information, the skills to start a conversation, change topics, and end the conversation, etc.

\section{COMPOSITION OF INTERCULTURAL COMMUNICATION SKILLS}

\section{A. Attitudes}

In the concept of intercultural communicative competence, attitudes mainly refer to the perceptions and expressions of the self-different views, values and behaviors of communicators, which are usually reflected in the long-established traditional concepts or prejudices of a society, and may also be the results through the practice of communicators' understanding. However, attitude is only a prerequisite for successful communication, and as such, only a positive attitude towards the social and cultural aspects involved is far from enough.

In order to achieve mutual communication, communicators need to be open and curious about the social cultures of each other, and even adopt the attitude of willingness to correct past biases, and analyze and re-understand the strengths and weaknesses of their own cultures from the perspective of interlocutors. Apparently, this attitude is an advanced stage of psychological development. It requires the communicators to be open-minded and consciously discover the features of other cultures, taking the initiative to deepen the understanding through contacts and social interaction with others. Of course, the formation of such an attitude is not an overnight thing. It takes a long time to accumulate and develop this attitude, and sometimes there may be some repetition. When communicators encounter difficulties, they should have the attitude of perseverance.

Therefore, education for developing the attitudes of intercultural communicative competence can be divided into several stages. In the early stage, it only requires the cultivation of a positive attitude, arousing the freshness and love of some products and behavioral manifestations (such as songs, short poems, basic necessities, etc.) of the foreign cultures. In the middle stage, stimulating the communicators' curiosity and interest of foreign cultures on the basis of the expansion of knowledge of foreign language, and make some simple comparisons with their native cultures. In the higher stage, enhancing the teaching of understanding of different views of world, life and value, etc., raising awareness of the overall social and cultural characteristics of the country in which the language is being learned.

\section{B. Knowledge}

The social and cultural knowledge required for the occasion of communication includes the following two aspects. One is the knowledge of the national social cultures of oneself and his conversation partners; the other is the knowledge of properly using the learned social and cultural norms to control communication process according to practical requirements. Relatively speaking, the former knowledge is easier to grasp. However, the latter knowledge needs a long period of learning and accumulation to command, and the success or failure of communication is often dependent on the level of knowledge and ability in this regard, so it should be given particular attention in the teaching process.

The first aspect of knowledge, especially the knowledge of one's own national cultures, is usually learned in the general context of family or school. Not only is media information in everyday life relevant to this aspect of knowledge, but also it is covered to varying degrees in some curricula, such as language, politics and history. However, the social and cultural knowledge of communicators, such as foreign cultures, is often strange to native students. Therefore, this requires the systematic stipulation of the content of foreign social and cultural knowledge in the syllabus of foreign language courses, which is implemented one by one in the course of teaching. Learning and mastery of the knowledge of the second aspect is more difficult. As many of the specific problems are temporarily generated in the communication process, they are really hard to predict. But it is believed that teachers can achieve certain teaching results if they can help students grasp the social and cultural norms to be followed in using language while providing students more opportunities to participate in the practice of teaching.

\section{Skills}

Foreign language learners need to grasp the following two aspects of social and cultural skills. One is to understand, explain and establish the relationship between the two cultures. The other is to find new information and then use it in communication. In other words, the first skill is to analyze the information based on the acquired social and cultural knowledge for the purpose of understanding and explanation after the information has been accepted, while the second skill is based on the first one, discovering new information and combining them together to provide communicators for use. The combination of these two skills enables the acquired social and cultural knowledge to be applied to the reality of communication.

It can be seen from the common characteristics of the two skills that although they can be obtained through different ways of classroom teaching or self-learning, the prerequisite is that they must be consciously learned and repeatedly practiced to be mastered rather than unconsciously acquired. Sometimes, since social and cultural information is hidden in the lines of the language, it is not as direct and explicit as the language itself, so it is hard to discover and understand the exact meaning. In addition to the English learning, the social and cultural norms of the foreign countries should also be understood. In fact, compared with English itself, intercultural communication skills are more difficult to master. Another 
characteristic of social and cultural skills is that they must be acquired in the process of communication. On the surface, sometimes the acquisition of social and cultural skills doesn't need the face-to-face communication, and information of society and cultures can be understood through effective reading. However, reading itself is a way of communication between authors and readers, which is considered as a silent exchange of information. If students want to firmly grasp the information through reading comprehension, they have to use the information multiple times. Therefore, the teaching of social and cultural skills can not only stay in the explanation of written materials, it should also provide more opportunities for students to participate in the communication practice. Thus, the ideal way is to interact with people who speak their native languages in various ways and get in touch with the original masterpieces and records.

The teaching and learning of foreign social and cultural attitudes, knowledge and skills cannot be completely separated, because they are closely related and complement each other. Attitude is the premise, if the students hold a negative attitude towards the foreign society and cultures, then learning knowledge and skills is just empty talk. Attitudes and knowledge provide the conditions for learning skills. In turn, the mastery of skills can lead to the development of a more positive attitude, and knowledge can be more consolidated. In addition, knowledge and skills are difficult to split apart, and the skills to understand information can only be built on the basis of knowledge.

\section{STRATEGIES OF CULTIVATING INTERCULTURAL COMMUNICATION}

\section{A. Attaching Importance to Cultural Teaching}

\section{1) Handling the relationship between language ability and} communicative competence properly

Only by understanding and mastering different cultural backgrounds can students recognize the verbal and nonverbal behaviors specific to the target cultures in various communicative activities, and understand and interpret their social functions so that they can consciously pay attention to the environment and occasions in which they use English. At the same time, they can consciously abide by the rules of using English to achieve the purpose of effective communication. It shows that having a certain knowledge of English does not mean that students can speak a well-regulated and proper language. The improvement of language ability is the foundation of cultivating communicative competence, and the positivity of communicative competence is the ultimate goal and task of language learning. In English teaching, teachers should not only pay attention to laying a solid foundation of English knowledge for students to help them master the correct language form, but also emphasize the cultivation of students' communicative competence so as to make both be compatible with each other. Finally, students can become both the masters and practitioners of English knowledge, who are able to communicate properly and appropriately in English [3].'
2) Cultivating students' awareness and sensitivity to intercultural communication

The acquisition of language ability lies in the mastery of language knowledge, and the key to obtain language ability is to have the awareness and sensitivity of intercultural communication. Generally, the sensitivity of cultural differences can be divided into four stages: the first stage is the identification of obvious cultural features on the surface, and the reactions of students are generally considered fresh and exotic. The second stage is the subtle but meaningful recognition of cultural features with different cultures, which is usually considered unbelievable or unacceptable. The third stage is similar to the second stage, but the difference is that it can be accepted through rational analysis. The fourth stage is to be able to feel cultures standing from each other's position.

These four stages construct a process of gradual and continuous improvement. Therefore, based on the specific conditions and teaching contents, teachers should selectively and properly compare and analyze the similarities and difference between Chinese and western cultures. For example, Western cultures advocate personal freedom while Chinese cultures emphasize collective interests; Westerners are afraid of getting old and avoid using "old" when possible, but Chinese think "old" is a symbol of seniority, dignity and authority; Chinese are not too concerned about privacy, but Westerners regard privacy as a forbidden zone. Through the comparison and analysis, students can recognize the commonalities of cultures from the different linguistic phenomena and find out the cultural differences among the linguistic phenomena with similar appearances, expand their own cultural horizons, and strongly feel the similarities and differences of English pragmatics rules, deepening the understanding of the principle of cultural communicability, thus to obtain a sense of intercultural communication and sensitivity.

\section{B. Coping with the Teaching Relationship Correctly}

On one hand, English is a practice-emphasized curriculum. In the process of teaching English knowledge and skills, teachers should also focus on cultivating students' ability of self-learning and self-improvement. In other words, teachers should help students find the most appropriate ways of self study [4]. With the traditional teacher-oriented teaching mode, it is often difficult for teachers to develop students' language ability. In the teacher-oriented classroom, students only passively accept knowledge, and they have little time to practice and think, which is detrimental to improve their initiative and creativity. In cognitive psychology, it shows that learning is a positive process of interaction, and in this process students are not only passive recipients of language form, but also language learning subjects and active creators. The teaching of English knowledge and skills needs to be completed through the practice of students, and the learning effect depends largely on the students' subjective initiative and participation. Nevertheless, the emphasis on students' positive initiative in the classroom is not to obliterate the role of teachers, on the contrary, it will increase the difficulty level of teaching and emphasize the guiding role of teachers. Furthermore, attention must be paid to highly developing students' leading role and teachers' guiding role during the 
teaching process. In such classrooms, teachers are designers and managers of classroom activities, participants, activists and collaborators of students' activities, as well as analysts and solvers of students' questions. In short, teachers become consultants and guides of students' learning. Teachers should pay attention to the learning characteristics and strategies of each student, properly give instructions and make adjustment of teaching methods so as to help students get the most out of learning. Such teaching and learning will certainly have special significance. In this way, teachers can provide a large number of effective input, create a relaxed learning environment, motivate students to actively learn, and guide students to selfcultivation of effective learning methods and self-study ability.

On the other hand, the background knowledge of foreign teachers can be fully used which is another main form of cultural teaching we have adopted over the years. Usually, the activities of foreign teachers reflect the cultural nature of English, having vivid cultural influences on students from dressing to lecturing. In many ways, such as nonverbal communication, the role of foreign teachers is irreplaceable. However, foreign teachers sometimes know little about students' mother tongue and cultures, and even give a slightest attitude to lead one-way communication. In this case, foreign teachers, on the one hand, recognize the importance of bilingualism and bilingualism, while on the other they maintain a monolingual and monocultural attitude. This will surely have a negative impact on students. As a result, what we have learned over these years is that it works better to employ foreign teachers who have typical foreign language cultures and intercultural teaching experience.

As Chinese teachers of English with the same background cultures as students, they have no obvious English culture background as foreign teachers, but they have the advantages of both bilingual and bicultural knowledge. Chinese English teachers themselves have proven the possibility of achieving bilingualism. However, they might be superficial for the comparisons if they don't have a deep understanding of native cultures and western cultures. Therefore, it is one of the necessary conditions for Chinese teachers to successfully carry out English teaching, constantly enriching foreign language and cultural knowledge while strengthening their study of Chinese cultures. At the same time, many teachers also expect to have a set of teaching materials and referencial books which aim at improving students' ability of language and intercultural communication, which is more conducive to teachers' introduction of different cultures.

\section{Strengthening the Cultivation of Chinese Cultural Awareness}

Although some students have learned English for many years, they still cannot achieve high language proficiency. In many cases, the misunderstanding of a language is not the problem of pronunciation, grammar or vocabulary, but students' lack of education and cultural competence, which leads to the lack of sensitivity to heterogeneous cultures and thus constitute an obstacle to intercultural communication. The same is true of mother tongue learning. From this, strengthening the competence of students' own language and cultures is an important way to cultivate their sense of cultural information. Language learning is a process of accumulation, the same with learning of culture. Language is based on cultures, so language and cultures cannot be separated in the learning process. English learners must understand the cultural connotation from the language, and find the most appropriate way to express English according to English cultures. Efforts to cultivate bilingual ability and bicultural competence are the keys to strengthening students' accomplishment of language and cultures. In fact, Chinese cultures is also one of the important factors to improve communicative competence [5].

In intercultural communication, topics and contents involved in a conversation are usually constrained to the cultural background of both sides. If the conversation is about Chinese traditional cultures, ethnic beliefs, marriage customs, food culture, social system, economic system, cultural monuments, scenic spots, etc. which students know nothing or know little about, they'll be put in a very embarrassing situation at the moment whatever strong communicative competence they have. Therefore, in English teaching, teachers should pay much attention to strengthening students' native culture awareness, guiding them to read newspapers and books on Chinese cultures in a planned, targeted and systematic manner, so that students will not only have certain English skills but also a complete knowledge structure, which can help students conduct various social activities more effectively, accurately and properly, and improve intercultural communication skills, thus to avoid a variety of pragmatic errors.

\section{CONCLUSION}

Language is a useful tool for communication, and English teaching is conducted through the study of literary and cultural knowledge of English. Therefore, English teaching should place a greater emphasis on understanding the experiences and opinions of English-speaking countries, society and people, interpreting and surpassing the potential concept students may hold. Through the systematic teaching of values, ethics, customs and legal systems of English cultures, students' awareness and cultural sensitivity will be greatly enhanced so that they can understand and respect different cultures, which is very helpful to reduce cultural conflicts and establish global cultural awareness. Finally, English teaching should be devoted to cultivating globalized talents facing the whole world, enable students to have transnational capabilities to adapt to global inspections and to share global resources.

\section{REFERENCES}

[1] D. F. Shu, Some Thoughts on Key Copetence for English as a Foreign Language in Chinese High Schools, J, Shandong Foreign Language Teaching, 2017(2), pp. 35-41.

[2] L. X. Song, Developing Intercultural Communication Competence and Teaching of Target Language Culture, J, Journal of Hubei Radio \& Television University, 2014(8), pp. 132-133.

[3] N. Tang, Attaching Importance to the English Teachers' Classroom Language and Cultivating the Students' Communicative Language Ability, J, Overseas English, 2014(15), pp. 92-93. 
[4] R. Li, Developing Students' Independent Learning Ability in English Teaching, J, Journal of Mudanjiang College of Education, 2004(3), pp. 87-88.

[5] M. J. He, Strenghtening Chinese Culturel Learning to Improve Intercultural Communicative Competence, J, Journal of Taiyuan Normal University(Social Science Edition), 2013(2), pp. 154-155. 